\title{
Effect of a novel PACAP-27 analogue on muscarinic airway responsiveness in guinea-pigs in vivo
}

\author{
A. Okazawa*, Z.-H. Cui*, J. Lötvall*, S. Yoshihara**, B-E. Skoogh*, K. Kashimoto+, A. Lindén*
}

Effect of a novel PACAP-27 analogue on muscarinic airway responsiveness in guinea-pigs in vivo. A. Okazawa, Z.-H. Cui, J. Lötvall, S. Yoshihara, B-E. Skoogh, K. Kashimoto, A. Lindén. @ERS Journals Ltd 1998.

ABSTRACT: A recent study showed that the novel pituitary adenylate cyclase-activating peptide (PACAP)-27 analogue [Arg15, 20, 21, Leu ${ }^{17}$-PACAP-27-Gly-Lys-Arg-NH ${ }_{2}$ causes sustained airway smooth muscle relaxation in vitro. This study examined whether this analogue also has bronchoprotective effects, by inhibiting muscarinic airway responsiveness in vivo.

Total lung resistance was measured in anaesthetized, tracheostomized and ventilated guinea-pigs. Increasing doses of acetylcholine were given $i . v$. once before and thereafter repeatedly each hour after intratracheal instillation of either the PACAP27 analogue or the clinical $\beta_{2}$-agonist bronchodilator salbutamol. Mean arterial blood pressure (MAP) was monitored to detect cardiovascular side-effects.

Both the PACAP-27 analogue and salbutamol significantly attenuated the airway responsiveness to acetylcholine. The total inhibitory effect of the PACAP-27 analogue $(350 \mathrm{nmol})$ corresponded to that of salbutamol $(35 \mathrm{nmol})$. The inhibitory effect of salbutamol $(35 \mathrm{nmol})$ peaked during the second hour and disappeared prior to $5 \mathrm{~h}$ after administration. In contrast, the corresponding effect of the analogue $(350 \mathrm{nmol})$ gradually increased and peaked during the fifth hour after administration, whereas it did not fade during the observation period. Both the PACAP-27 analogue $(350 \mathrm{nmol})$ and salbutamol $(35 \mathrm{nmol})$ produced a transient decrease in MAP within 6 min after administration.

In conclusion, the novel pituitary adenylate cyclase-activating peptide-27 analogue has bronchoprotective properties, by decreasing muscarinic airway responsiveness in guinea pigs in vivo. The time course of its effect is compatible with a more sustained duration of action compared with salbutamol.

Eur Respir J 1998; 12: 1062-1066.
*Lung Pharmacology Group, Dept of Respiratory Medicine and Allergology, Göteborg University, Göteburg, Sweden. **First Dept of Pediatrics, Dokkyo University School of Medicine, Tochigi, Japan. +Ito Ham Central Research Institute, Ibaraki, Japan.

Correspondence: A. Lindén, Lung Pharmacology Group, Göteborg University, Guldhedsgatan 10 A, S-413 46, Göteborg, Sweden Fax: 4631413290

Keywords: Acetylcholine, airway responsiveness, bronchodilator, lung resistance, pituitary adenylate cyclase-activating peptide, salbutamol

Received: January 151998

Accepted after revision July 51998

Supported by the Hermann Krefting Asthma and Allergy Foundation, Ito Ham Central Research Institute, the Swedish Heart-Lung Foundation, the Swedish Medical Research Council (K97-04X-09-04-8-08A, U1268), the Swedish Environmental Work Foundation and the Vårdal Foundation.
The pituitary adenylate cyclase-activating peptides (PACAPs) are vasoactive intestinal peptide (VIP)-like neuropeptides existing in a 38 and a 27 -amino acid residue form $[1,2]$, named PACAP-38 and PACAP-27, respectively, with an identical 1-27 amino acid sequence. Immunoreactivity for PACAPs has been demonstrated close to smooth muscle in airways from humans and other mammals such as the guinea-pig [3-5]. It has also been shown that PACAP-38 or PACAP-27 relaxes guinea-pig and rabbit airway smooth muscle, at least in part by increasing adenosine 3',5'-cyclic monophosphate (cAMP) in vitro [6, 7]. In vivo, inhaled PACAP-27 or PACAP-38 causes significant bronchodilation with a rapid onset of action without severe cardiovascular side-effects in guinea-pigs [8, 9]. Recently, it has been reported that a novel amino and carboxy-terminally modified PACAP-27 molecule, [Arg15, 20, 21, Leu ${ }^{17}$ ]-PACAP-27-Gly-Lys-Arg-NH, relaxes primate and guinea-pig airway smooth muscle in vitro with a more sustained duration of action than unmodified PACAP-27 [10]. Until now, this novel PACAP-27 analogue has not been tested in vivo.

The aim of the present study was to determine whether airway administration of this novel PACAP-27 analogue in- hibits muscarinic airway responsiveness in vivo and if so, what the time course of this bronchoprotective effect is compared with the bronchodilating $\beta_{2}$-agonist salbutamol. The present study also examined whether or not the PACAP-27 analogue causes significant cardiovascular side-effects.

\section{Materials and methods}

\section{Animal preparation}

This study was approved by the Animal Study Ethics Committee at Göteborg University. Male Dunkin-Hartley guinea-pigs (400-600 g) were used. The animals were anaesthetized with $1 \mathrm{~mL} \cdot \mathrm{kg}^{-1}$ of a $3: 2$ mixture of ketamine $\left(50 \mathrm{mg} \cdot \mathrm{mL}^{-1}\right)$ and xylazine $\left(20 \mathrm{mg} \cdot \mathrm{mL}^{-1}\right)$ by intramuscular injection. Additional doses were given as required to maintain an adequate level of anaesthesia, as demonstrated by no withdrawal response to foot-pad pinching. The animals were placed on a heated blanket (Harvard model 50-7061; Harvard Apparatus, Edenbridge, UK) to maintain body temperature at approximately $38^{\circ} \mathrm{C}$. 
The left carotid artery was cannulated and the catheter filled with heparin-saline $\left(10 \mathrm{U} \cdot \mathrm{mL}^{-1}\right)$ and connected to a pressure transducer (model P23XL; Viggo-Spectramed, Helsingborg, Sweden) to monitor the mean arterial blood pressure (MAP) throughout the experiments. Another polyethylene catheter was inserted into the right external jugular vein for the administration of drugs. A tracheal cannula (10 mm length and $2.7 \mathrm{~mm}$ outer diameter) was inserted into the upper cervical trachea through a tracheostomy, s-ecured with a suture and connected to a constant volume mechanical ventilator (Harvard model 501718; Harvard Apparatus). Animals were placed in a supine position at an angle of $20^{\circ}$, with the head at an elevated level to allow the instilled drug to reach the lower airways. A tidal volume of $10 \mathrm{~mL} \cdot \mathrm{kg}^{-1}$ and a respiratory frequency of 60 breaths $\cdot \mathrm{min}^{-1}$ were used. The ventilatory circuit had a total volume of $18 \mathrm{~mL}$.

Transpulmonary pressure was measured using a differential pressure transducer $\left( \pm 1,000 \mathrm{mmH}_{2} \mathrm{O}\right.$, Model FCO44; Furness Controls, Bexhill, UK), with one side attached to a catheter connected to a side port of the intratracheal cannula and the other side attached to a catheter into the right pleural cavity. Airflow was measured with a pneumotachograph (Model F1L; Mercury Electronics, Glasgow, UK) connected to a transducer $\left( \pm 20 \mathrm{mmH}_{2} \mathrm{O}\right.$, Model FCO40; Furness Controls). The signals from the transducers were amplified with an analogue preamplifier (Kungsbacka Mät\& Reglerteknik, Kungsbacka, Sweden), digitized using a 12-bit analogue-digital board (National Instruments, Austin, TX, USA) connected to a Macintosh II computer (Apple Computer, Cupertino, CA, USA) and monitored with customized software (LabView; National Instruments) programmed to calculate lung resistance $(R \mathrm{~L})$ instantaneously according to the method of von NEERGAard and WIRZ [11].

\section{Study design}

Each animal received intratracheal (i.t.) instillation of $100 \mu \mathrm{L}$ of drug or vehicle solution, followed by $1 \mathrm{~mL}$ of air through a needle inserted directly into the tracheal lumen via the tracheal cannula as described previously [12]. Three different treatment groups were included: the vehicle-treated group (instillation of sterile phosphate-buffered saline (PBS); $\mathrm{n}=7$ ), the PACAP-27 analogue-treated group (instillation of PACAP-27 analogue $350 \mathrm{nmol} ; \mathrm{n}=4$ ) and the salbutamol-treated group (instillation of salbutamol hemisulphate $35 \mathrm{nmol} ; \mathrm{n}=5$ ). The doses of the PACAP-27 analogue and salbutamol were chosen based on separate dose-response experiments, indicating a significant protective effect, i.e. the area under the curve (AUC) for the within-animal shift in the provocative dose of acetylcholine causing a $400 \%$ increase in $R \mathrm{~L}$ above baseline from 1$5 \mathrm{~h}(\mathrm{AUC} 1-5 \mathrm{~h}$ of $\Delta \log 10 \mathrm{PD} 400 R \mathrm{~L}$ ) at these doses (data not shown). Each instillation into the trachea was conducted $30 \mathrm{~min}$ after the initial acetylcholine challenge described below.

\section{Muscarinic airway responsiveness}

Thirty minutes of equilibration followed the animal preparation described above. An initial acetylcholine challenge was then conducted to determine the airway res- ponsiveness before drug instillation. Exactly the same procedure was followed for acetylcholine challenge at 1,2, 3,4 and $5 \mathrm{~h}$ after drug instillation. After measuring baseline $R \mathrm{~L}$, four successive i.v. bolus injections of acetylcholine $\left(6.25,12.5,25\right.$ and $\left.50 \mu \mathrm{g} \cdot \mathrm{kg}^{-1}\right)$ were performed at 5 min intervals. After each injection, $R \mathrm{~L}$ and MAP were recorded every $15 \mathrm{~s}$ over $1 \mathrm{~min}$ and subsequently every $30 \mathrm{~s}$ for another $2 \mathrm{~min}$. The maximum increase in $R \mathrm{~L}$ induced by each dose of acetylcholine was measured and this maximum occurred within $30 \mathrm{~s}$ after the administration of acetylcholine. In exceptional cases, when transpulmonary pressure exceeded $50 \mathrm{cmH}_{2} \mathrm{O}$, the challenge was stopped to prevent animal mortality. At 3 min after each acetylcholine injection, lungs were hyperinflated once as described below, then $R \mathrm{~L}$ returned towards the baseline. When necessary, the tracheal cannula was cleared of secretions by suction with a $10 \mathrm{~mL}$ syringe through a polyethylene catheter, positioned inside the tracheal cannula, between the acetylcholine challenges. After drug instillation, $R \mathrm{~L}$ and MAP were recorded every $15 \mathrm{~s}$ over $1 \mathrm{~min}$ and subsequently every 30 $\mathrm{s}$ for another $5 \mathrm{~min}$. Six min after instillation, the lungs were hyperinflated once with twice the tidal volume, by manually blocking the outflow of the ventilator.

\section{Materials}

Acetylcholine chloride and salbutamol hemisulphate were purchased from Sigma Chemical Co. (St Louis, MO, USA), ketamine hydrochloride from Parke-Davis (Barcelona, Spain), xylazine chloride from Bayer Sverige (Göteborg, Sweden) and heparin sodium from Løvens Kemiske Fabrik (Ballerup, Denmark). The PACAP-27 analogue [10] was synthesized by Ito Ham Central Research Institute Co. (Ibaraki, Japan). Its amino acid sequence has been described elsewhere [10]. Both the PACAP-27 analogue and salbutamol were dissolved in sterile PBS. Acetylcholine was dissolved in sterile saline.

\section{Statistical analysis}

The provocative dose of acetylcholine causing a $400 \%$ increase in $R \mathrm{~L}$ above baseline (PD400 $R \mathrm{~L}$ ), was calculated by linear interpolation of the dose-response curve in each animal. PD400 $R \mathrm{~L}$ values were $\log 10$ transformed prior to analysis. To evaluate the change in PD $400 R \mathrm{~L}$ the withinanimal shift, $\Delta \log 10 \mathrm{PD} 400 R \mathrm{~L}$ (the $\log 10 \mathrm{PD} 400 R \mathrm{~L}$ at each acetylcholine challenge minus the $\log 10 \mathrm{PD} 400 R \mathrm{~L}$ at the initial acetylcholine challenge) was calculated. Furthermore, the $\mathrm{AUC}_{1-5} \mathrm{~h}$ of $\Delta \log 10-\mathrm{PD} 400 R \mathrm{~L}$ during the observation period was calculated to evaluate the total effect of treatment. MAP was analysed in two ways: the peak change within 6 min after instillation i.t. of drugs was calculated as per cent of baseline MAP prior to drug instillation i.t. (\% baseline) and the change in MAP was also calculated as AUC to assess the total effect throughout the observation period. Unless otherwise stated, data are reported as the geometric mean \pm SEM. Analysis of variance (ANOVA) was used to determine any significant variance among groups. If a significant variance was found, the Fischer's prevented least significant difference test (Fischer's PLSD) was subsequently used to determine the significant differences between individual groups. A pð0.05 was considered significant. 


\section{Results}

Lung resistance and muscarinic airway responsiveness at baseline

The (mean $\pm \mathrm{SD}$ ) baseline $R \mathrm{~L}$ prior to the initial acetylcholine challenge was $0.18 \pm 0.01 \mathrm{cmH}_{2} \mathrm{O} \cdot \mathrm{mL}^{-1} \cdot \mathrm{s} \quad(\mathrm{n}=4)$ in guinea-pigs receiving the PACAP-27 analogue $(350 \mathrm{nmol})$, $0.17 \pm 0.04 \mathrm{cmH}_{2} \mathrm{O} \cdot \mathrm{mL}^{-1} \cdot \mathrm{s}(\mathrm{n}=5)$ in guinea-pigs receiving salbutamol $(35 \mathrm{nmol})$ and $0.20 \pm 0.02 \mathrm{cmH}_{2} \mathrm{O} \cdot \mathrm{mL}^{-1} \cdot \mathrm{s}(\mathrm{n}=7)$ in guinea-pigs receiving vehicle; these values were not significantly different (ANOVA: $\mathrm{F}=1.47, \mathrm{p}=0.26$ ). The i.t. instillation of bronchodilators and vehicle did not alter this baseline RL (data not shown).

Figure 1 shows the initial response to cumulatively increasing doses of acetylcholine in each respective treatment group. The (mean \pm SEM) initial reactivity to acetylchol- ine $(\log 10 \mathrm{PD} 400 R \mathrm{~L})$ was $1.31 \pm 0.14$ prior to the PACAP-27 analogue $(n=4), 1.19 \pm 0.13$ prior to salbutamol $(n=5)$ and $1.19 \pm 0.07$ prior to vehicle $(n=7)$. This parameter did not differ significantly (ANOVA: $\mathrm{F}=0.92, \mathrm{p}=0.42$ ) bet-ween groups.

Change in muscarinic airway responsiveness during repeated acetylcholine challenge

At the initial acetylcholine challenge in the vehicle-treated guinea-pigs, the mean PD400 $R \mathrm{~L}$ and $\log 10 \mathrm{PD} 400 R \mathrm{~L}$ were 15.5 and $1.19 \pm 0.07 \mu \mathrm{g} \cdot \mathrm{mL}^{-1}$, respectively. During the repeated acetylcholine challenge in these guinea-pigs, the muscarinic reactivity was somewhat increased; the $\log 10$ PD400 RL was moderately but significantly reduced (ANOVA: $\mathrm{F}=3.6, \mathrm{p}=0.02, \mathrm{n}=7$ ) compared with the initial $\log 10 \mathrm{PD} 400$ $R \mathrm{~L}$ to $1.10 \pm 0.07$ at $1 \mathrm{~h}$ (Fischer's PLSD: $\mathrm{p}=0.23, \mathrm{n}=7$ ), $1.00 \pm 0.06$ at $2 \mathrm{~h}$ (Fischer's PLSD: $\mathrm{p}=0.02, \mathrm{n}=6-7), 0.92 \pm$ 0.05 at $3 \mathrm{~h}$ (Fischer's PLSD: $\mathrm{p}=0.002, \mathrm{n}=6-7), 0.93 \pm 0.02$ at $4 \mathrm{~h}$ (Fischer's PLSD: $\mathrm{p}=0.003, \mathrm{n}=6-7)$ and $0.97 \pm 0.06$ at 5 h (Fischer's PLSD: $\mathrm{p}=0.01, \mathrm{n}=5-7$ ).

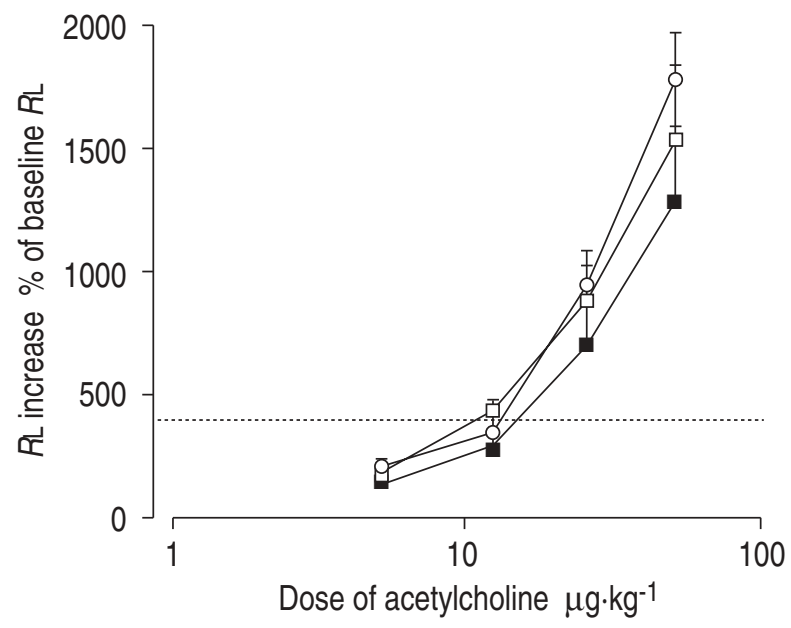

Fig. 1. - Dose-response data presented as increase (\%) in lung resistance $(R \mathrm{~L})$ above baseline for the initial acetylcholine challenge in each individual treatment group, before the administration of bronchodilators. The intersection with the dashed line indicates provocative dose of acetylcholine causing a $400 \%$ increase in RL above baseline (PD400 RL). Data for groups before treatment with the pituitary adenylate cyclase-activating peptide (PACAP)-27 analogue ( $350 \mathrm{nmol}, \mathbf{\square})$ salbutamol $(35 \mathrm{nmol}, \square)$ and vehicle $(O)$ are presented as mean with SEM ( $n=4-7$ per group).

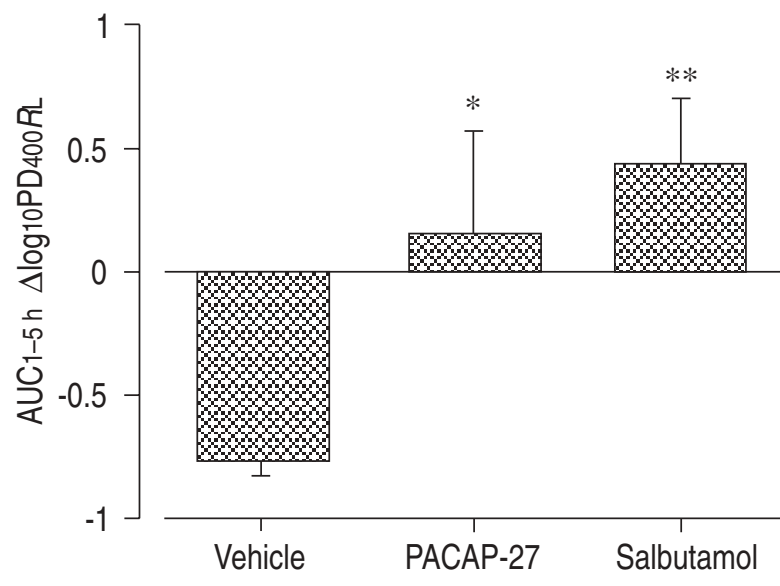

Fig. 2. - Total protective effect over $5 \mathrm{~h}$, assessed as change in the area under the curve (AUC) for the within-animal shift in the provocative dose of acetylcholine causing a $400 \%$ increase in lung resistance (RL) above baseline $1-5 \mathrm{~h}(\mathrm{AUC} 1-5 \mathrm{~h} \Delta \log 10 \mathrm{PD} 400 R \mathrm{~L})$ for the pituitary adenylate cyclase-activating protein (PACAP)-27 analogue, salbutamol and vehicle. The $\mathrm{AUC}_{1-5} \mathrm{~h} \Delta \log 10 \mathrm{PD} 400 R \mathrm{~L}$ differed significantly among groups (analysis of variance: $\mathrm{F}=4.47, \mathrm{p}=0.014, \mathrm{n}=4-7$ ). *: pð0.05, **: $\mathrm{p}<0.01$ versus vehicle, according to Fischer's prevented least significant difference test. Data are presented as mean with SEM ( $n=4-7$ per group).

\section{Total and peak effect on muscarinic airway responsiveness}

The total protective effect throughout the observation period, reflected by the $\mathrm{AUC} 1-5 \mathrm{~h}$ of $\Delta \log 10 \mathrm{PD} 400 R \mathrm{~L}$, is shown for each treatment in figure 2. The PACAP-27 analogue $(350 \mathrm{nmol})$ increased the $\mathrm{AUC} 1-5 \mathrm{~h}$ of $\Delta \log 10 \mathrm{PD} 400$ $R \mathrm{~L}$ significantly compared with vehicle, as did salbutamol ( $35 \mathrm{nmol})$. Compared with the vehicle group, the increase in $\mathrm{AUC}_{1-5} \mathrm{~h}$ of $\Delta \log 10 \mathrm{PD} 400 R \mathrm{~L}$ caused by the PACAP-27 analogue was approximately $75 \%$ of that caused by salbutamol.

The peak effect, reflected by the peak $\log 10 \mathrm{PD} 400 \mathrm{RL}$ during the five-hour observation period, was $0.18 \pm 0.08$ for the PACAP-27 analogue (Fischer's PLSD: $\mathrm{p}=0.02, \mathrm{n}=4$ ) and $0.37 \pm 0.07$ for salbutamol (Fischer's PLSD: $p=0.001$, $\mathrm{n}=5$ ), which was significantly different (ANOVA: $\mathrm{F}=13.0$, $\mathrm{p}=0.001$ ) from the $-0.08 \pm 0.05$ observed in the vehicle group $(n=7)$.

Time course of the effect on muscarinic airway responsiveness

The PACAP-27 analogue (350 nmol) displayed a slow onset of action; it increased the $\Delta \log 10 \mathrm{PD} 400 R \mathrm{~L}$ significantly from $4 \mathrm{~h}$ onwards after i.t. instillation, as shown in figure 3 . In contrast, salbutamol $(35 \mathrm{nmol})$ displayed a more rapid onset of action; it increased $\Delta \log 10 \mathrm{PD} 400 R \mathrm{~L}$ significantly from $1 \mathrm{~h}$ until $4 \mathrm{~h}$ after i.t. instillation. Salbutamol caused no significant effect at $5 \mathrm{~h}$ after i.t. instillation.

The different treatment groups differed significantly in time until the peak $\Delta \log 10 \mathrm{PD} 400 R \mathrm{~L}$ (ANOVA: $\mathrm{F}=7.1, \mathrm{p}=$ $0.01, n=4-7)$. This time was significantly longer for the PACAP-27 analogue $(4.5 \pm 0.3 \mathrm{~h})$ than for either salbutamol $(1.6 \pm 0.7 \mathrm{~h}$; Fischer's PLSD: $\mathrm{p}=0.005, \mathrm{n}=4-5)$ or vehicle $(1.8 \pm 0.6 \mathrm{~h}$; Fischer's PLSD: $\mathrm{p}=0.006, \mathrm{n}=4-7)$. 


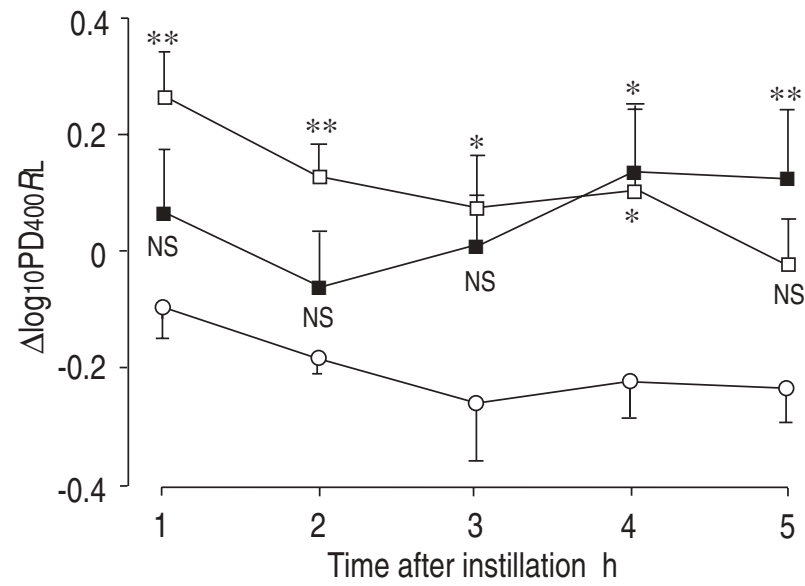

Fig. 3. - Time course of the within-animal shift in the provocative dose of acetylcholine causing a $400 \%$ increase in lung resistance above baseline $(\Delta \log 10 \mathrm{PD} 400 R \mathrm{~L})$ after administration of the pituitary adenylate cyclase-activating peptide (PACAP)-27 analogue (350 nmol, a), salbutamol $(35 \mathrm{nmol}, \square)$ and vehicle (O). The $\Delta \log 10 \mathrm{PD} 400 R \mathrm{~L}$ differed significantly among groups over time (analysis of variance: $F=4.6-8.0$, pð $0.03, \mathrm{n}=4-7)$. *: pð0.05, **: $\mathrm{p}<0.01$, Ns: $\mathrm{p}>0.05$ versus vehicle, according to Fischer's prevented least significant difference test. Data are presented as mean with SEM ( $n=4-7$ per group).

\section{Effect on arterial blood pressure}

The peak change in MAP is shown for each treatment group in table 1. Figure 4 shows the corresponding time course for MAP. Before the administration of the drugs, there was no significant difference in MAP between groups (table 1). After instillation i.t., there was no significant variance in AUC for the five-hour observation period (AUC1-5 h of MAP) for the groups studied, as demonstrated in table 1 . However, both the PACAP-27 analogue and salbutamol caused transient, but statistically significant, hypotension, always within $6 \mathrm{~min}$ after i.t. instillation (table 1).

\section{Discussion}

Intratracheal instillation of the novel PACAP-27 analogue inhibited the airway responsiveness to acetylcholine given i.v. in guinea-pigs in vivo. The onset of action for

Table 1. - Effect of the pituitary adenylate cyclase-activating peptide (PACAP)-27 analogue and salbutamol on mean arterial blood pressure (MAP)

\begin{tabular}{lcccc}
\hline Pretreatment & $\mathrm{n}$ & $\begin{array}{c}\text { MAPbaseline } \\
\mathrm{mmHg}\end{array}$ & $\begin{array}{c}\text { Peak change } \\
0-6 \text { min } \\
\%\end{array}$ & $\begin{array}{c}\text { AUC0-5 h } \\
\text { of MAP } \\
\mathrm{mmHg} \cdot \mathrm{h}^{-1}\end{array}$ \\
\hline $\begin{array}{l}\text { Vehicle } \\
\text { PACAP-27 ana- } \\
\begin{array}{l}\text { logue 350 nmol } \\
\text { Salbutamol }\end{array}\end{array}$ & 4 & $53 \pm 4 \mathrm{Ns}^{1}$ & $-7 \pm 4$ & $250 \pm 14 \mathrm{Ns}^{2}$ \\
$35 \mathrm{nmol}$ & 5 & $56 \pm 3 \mathrm{Ns}^{1}$ & $-51 \pm 5 * * *$ & $247 \pm 90 \mathrm{Ns}^{2}$ \\
\hline
\end{tabular}

Data are presented as mean \pm SEM. Peak change $0-6$ min: peak change in MAP 0-6 min after intratracheal instillation; AUC0-5 $\mathrm{h}$ of MAP: area under the MAP curve $0-5 \mathrm{~h}$ after intratracheal instillation. ***: $\mathrm{p}<0.001$ versus vehicle according to Fischer's prevented least significant difference (PLSD) test preceded by analysis of variance (ANOVA): $\mathrm{F}=37.6, \mathrm{p}=0.0001$. $\mathrm{NS}^{1}$ : nonsignificant ANOVA: $\mathrm{F}=0.40, \mathrm{p}=0.68$; $\mathrm{Ns}^{2}$ : nonsignificant ANOVA: $\mathrm{F}=0.46, \mathrm{p}=0.64$.

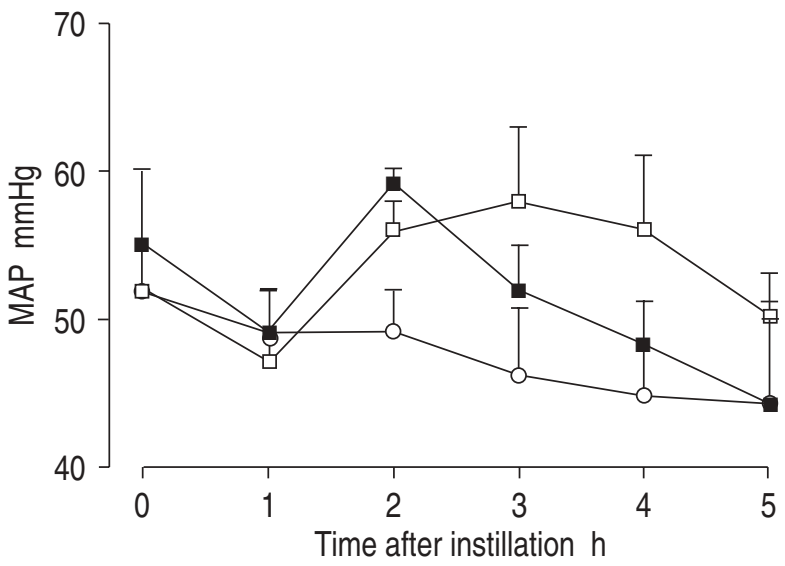

Fig. 4. - Time course of mean arterial blood pressure (MAP) after administration of the pituitary adenylate cyclase-activating peptide (PACAP)27 analogue (350 nmol, $\mathbf{\square})$, salbutamol $(35 \mathrm{nmol}, \square)$ and vehicle (O). Data are presented as mean with SEM ( $n=4-7$ per group).

this bronchoprotective effect by the PACAP-27 analogue was slower than that of salbutamol given in a dose with a similar total effect over $5 \mathrm{~h}$. The PACAP-27 analogue, but not salbutamol, still caused a significant rightward shift of the dose-response curve to acetylcholine $5 \mathrm{~h}$ after administration.

The $\beta_{2}$-adrenoceptor agonist salbutamol was utilized as a reference bronchodilator. As indicated by the total bronchoprotective effect during $5 \mathrm{~h}$ (AUC1-5 h of $\Delta \log 10 \mathrm{PD} 400$ $R \mathrm{~L}$ ), produced by the PACAP-27 analogue and salbutamol, respectively, the peptide molecule is approximately one-tenth as potent as salbutamol on a molar basis in guinea-pigs. This observation is supported by preliminary experiments (data not shown), which indicated that the total effect produced by $35 \mathrm{nmol}$ of the PACAP-27 analogue corresponds to that of $3.5 \mathrm{nmol}$ of salbutamol, (both instilled i.t.). Whereas the original PACAP-27 molecule displays a similar potency to the PACAP-27 analogue in guineapig airways in vitro [10], it is less potent than salbutamol in this tissue. In contrast, the PACAP-27 analogue is equipotent to salbutamol in primate bronchi in vitro [10]. It is, therefore, uncertain whether the PACAP-27 analogue is less potent than salbutamol in primate bronchi.

The time course of the effect of the PACAP-27 analogue on muscarinic airway responsiveness $(\log 10 \mathrm{PD} 400$ $R \mathrm{~L})$ suggests a slower, but more sustained action than that of salbutamol. Because the design of the current study did not allow any assessment of the effect of the PACAP-27 analogue beyond $5 \mathrm{~h}$ after administration, it is not possible to make any valid conclusion regarding the time limit of action for this novel peptide molecule in this airway model. It is clear, however, that the effect of the tested dose of salbutamol disappeared after $4 \mathrm{~h}$ of administration, confirming the limited duration of action for this bronchodilator. The molecular basis for the sustained effect of the PACAP-27 analogue is not fully understood. In primate bronchi and in the guinea-pig trachea in vitro, the long duration of action of the analogue is at least in part due to its resistance to peptidase degradation [10]. The original PACAP-38 molecule, which consists of PACAP-27 plus an additional 11 amino acids, contains basic amino acids at the carboxy-terminal, as does the current PACAP-27 analogue [13]. This basic nature of additional amino acids 
may, therefore, contribute to the sustained action of PACAP-38 [9, 14, 15] and the PACAP-27 analogue. Further studies will be required to determine whether or not the size of the novel PACAP-27 analogue (molecular weight $3,600 \mathrm{Da}$ ) and its eventual lipophilic properties also contribute to its sustained duration of action.

There were no significant differences in the total effect on blood pressure during $5 \mathrm{~h}$ (AUC1-5 h of MAP) after administration of either the PACAP-27 analogue or salbutamol, compared with vehicle during the five-hour observation period. This suggests that the PACAP-27 analogue causes no sustained, severe cardiovascular side-effects at a dose causing significant bronchoprotection. The transient hypotension, which was observed within 6 min after administration of the PACAP-27 analogue or salbutamol, is difficult to attribute to a mechanism involving receptor activation and cAMP elevation, at least for the PACAP-27 analogue. This is because of the substantial difference in time course of the induced hypotension versus the bronchoprotective effect of the analogue.

It is likely that the transient hypotension caused by salbutamol and the PACAP-27 analogue is the consequence of a rapid change in airway osmolarity, due to the intratracheal instillation procedure per se. This explanation is supported by several observations. Firstly, preliminary experiments showed that at $35 \mathrm{nmol}$ and $350 \mathrm{nmol}$, respectively (data not shown) the PACAP-27 analogue and salbutamol caused transient hypotension of a similar magnitude, whereas the vehicle, with its low osmolarity, did not. Secondly, a recent comparison of inhaled PACAP-27 and PACAP-38 in guinea-pigs in vivo showed no cardiovascular side-effects at doses causing significant bronchodilation [9]; inhalation probably leads to a lower topical concentration than does instillation i.t. Third, infusion $i . v$. of the original PACAP-27 does not cause cardiovascular side-effects at doses causing bronchodilation in guinea-pigs in vivo [8]. In addition, instillation i.t. of allergen causes transient hypotension in unsensitized guineapigs, using the same airway model and set-up [16].

In conclusion, this study in guinea-pigs indicates that a novel amino and carboxy-terminal modified pituitary adenylate cyclase-activating peptide- 27 analogue produces a significant and sustained inhibitory effect on muscarinic airway responsiveness after airway administration in vivo. This novel analogue therefore deserves further evaluation regarding its potential as an inhaled, long-acting bronchodilator.

\section{References}

1. Miyata A, Arimura A, Dahl RR, et al. Isolation of a novel 38 residue-hypothalamic polypeptide which stimulates adenylate cyclase in pituitary cells. Biochem Biophys Res Commun 1989; 164: 565-574.

2. Miyata A, Jiang L, Dahl RD, et al. Isolation of a neuropeptide corresponding to the $\mathrm{N}$-terminal 27 residues of the pituitary adenylate cyclase activating polypeptide with 38 residues (PACAP38). Biochem Biophys Res Commun 1990; 170: 643-648.

3. Cardell LO, Uddman R, Luts A, Sundler F. Pituitary adenylate cyclase activating peptide (PACAP) in guinea-pig lung: distribution and dilatory effects. Regul Pept 1991; 36: 379-390.

4. Uddman R, Luts A, Arimura A, Sundler F. Pituitary adenylate cyclase-activating peptide (PACAP), a new vasoactive intestinal peptide (VIP)-like peptide in the respiratory tract. Cell Tissue Res 1991; 265: 197-201.

5. Luts A, Uddman R, Alm P, Basterra J, Sundler F. Peptidecontaining nerve fibers in human airways: distribution and coexistence pattern. Int Arch Allergy Immunol 1993; 101: 52-60.

6. Araki N, Takagi K. Relaxant effect of pituitary adenylate cyclase-activating polypeptide on guinea-pig tracheal smooth muscle. Eur J Pharmacol 1992; 216: 113-117.

7. Kanemura T, Tamaoki J, Chiyotani A, et al. Role of $\mathrm{Na}^{+-}$ $\mathrm{K}^{+}$-ATPase in airway smooth muscle relaxation by vasoactive intestinal peptide and pituitary adenylate cyclase activating peptide. Res Commun Chem Pathol Pharmacol 1993; 79: 11-22.

8. Lindén A, Yoshihara S, Chan B, Nadel JA. Inhibition of bronchoconstriction by pituitary adenylate cyclase activating polypeptide (PACAP 1-27) in guinea-pigs in vivo. Br J Pharmacol 1995; 115: 913-916.

9. Lindén A, Cardell LO, Yoshihara S, Stjärne P, Nadel JA. PACAP 1-38 as an inhaled bronchodilator in guinea pigs in vivo. Peptides 1998; 19: 93-98.

10. Yoshihara S, Lindén A, Kashimoto K, Nagano Y, Ichimura T, Nadel JA. Long lasting smooth muscle relaxation by a novel PACAP analogue in guinea-pig and primate airways in vitro. Br J Pharmacol 1997; 121: 1730-1734.

11. von Neergaard K, Wirz K. Die Messung der Strömungswiderstände in den Atemwegem des Menschen, insbesondere bei Asthma und Emphysem. Z Klin Med 1927; 105: 51-82

12. Kawikova I, Arakawa H, Löfdahl CG, Skoogh BE, Lötvall J. Bradykinin-induced airflow obstruction and airway plasma exudation: effects of drugs that inhibit acetylcholine, thromboxane $\mathrm{A}_{2}$ or leukotrienes. $\mathrm{Br} \mathrm{J}$ Pharmacol 1993; 110: 657-664.

13. Kashimoto K, Nagano Y, Suitani Y, et al. Structure-activity relationship studies of PACAP-27 and VIP analogues. Ann NY Acad Sci 1996; 805: 505-510.

14. Nandha KA, Benito-Orfila MA, Smith DM, Ghatei MA, Bloom SR. Action of pituitary adenylate cyclase-activating polypeptide and vasoactive intestinal polypeptide on the rat vascular system: effects on blood pressure and receptor binding. J Endocrinol 1991; 129: 69-73.

15. Ishizuka Y, Kashimoto K, Mochizuki T, Sato K, Ohshima K, Yanaihara N. Cardiovascular and respiratory actions of pituitary adenylate cyclase-activating polypeptides. Regul Pept 1992; 40: 29-39.

16. Arakawa H, Lötvall J, Kawikova I, et al. Airway allergy to trimellitic anhydride in guinea pigs: different time courses of $\mathrm{IgG} 1$ titer and airway responses to allergen challenge. J Allergy Clin Immunol 1993; 92: 425-434. 